\title{
Simulation Model of The Collision Event of Submarine Mudflows Exerting A Horizontal Pipeline
}

\author{
Zainul Faizien Haza, Indra Sati Hamonangan Harahap
}

\begin{abstract}
The collision between submarine slide and sub-sea pipelines was simulated through laboratory experiment in order to investigate drag force exerted by mudflow on pipe surface. Mud model used was slurry of kaolin clay-water mixtures. Gravity flow concepts of fluid mechanics principles were implemented by lock-exchange system. It was developed through the laboratory equipment of rectangular channel to generate the mudflow in water ambient. A crosswise pipe stem positioned at certain run-out distance. It was collided by mudflow. The collision attributes of velocity $(u)$, Reynolds number $(R e)$, maximum drag force exerted by mudflow $\left(F d_{\text {max }}\right)$ and drag force coefficient $(\boldsymbol{C d})$ were observed based on ratio between water depth (at pipe position) and pipe diameter, abbreviated as $H / d$. Overall, higher $H / d$ ratio generated higher values of collision attributes. $H / d$ ratio variations had similar constant of Power-law model expression in $\mathrm{Re}-\mathrm{Cd}$ relationship. It proved that $\mathrm{H} / \mathrm{d}$ ratio had not effect to $C d$ very much. The current experiment also generated a high similarity trend line of $R e-C d$ relationship graph with the previous study. It indicated that the content of clay material (i.e. kaolin) play a major role in mudflow movement and collision, whereas granular materials (used in previous study) provide an extra density.
\end{abstract}

Keywords - submarine slide, mudflow, kaolin clay, lockexchange, gravity flow, drag force coefficient.

\section{Introduction}

Submarine slide is one of the geo-hazards which has now become a serious and complex problem in the marine field because it has detrimental consequences against offshore installations such as fixed platforms, submarine pipelines, cables and other seafloor installations as well as people and infrastructure along the coastlines [1-2]. As consequences of rapid development of oil and gas industry, which is moving to depth over $1000 \mathrm{~m}$ along or in propinquity of the continental slope [3], pipelines installation are subjected to such geologically hazardous condition.

Mudflows, one type of submarine slide, presents movement as the most effective process of sediment transport from the shallow continental margin into the deep ocean [4].

Zainul Faizien Haza

Universitas Sarjanawiyata Tamansiswa Indonesia

Indra Sati Hamonangan Harahap

Universiti Teknologi PETRONAS

Malaysia
Some researchers pointed out that the submarine slide could reach very long run-out distance up to hundreds of kilometers on a gentle slope [4-7] and involved cohesive finegrained material, i.e. clays and silts [6]. Furthermore, some researches characterized kaolin as the most predominant clay mineral contained in seafloor sediment [8-10]. That is in line with the findings that in terrigenous clastic sediment, muddy material dominated the schematic of sediment deposits [11].

Facilities and infrastructure damages caused by the underwater flow of submarine mudslides, especially pipelines, are the major concern in the scope of the seabed geohazard study. Not only respecting to the high annual cost of the damage, which was about US $\$ 400$ million as estimated by The Society for Underwater Technology [12], but also mainly about the events of the collision between the mudflow with pipelines. In this case, the interaction between the two generates a force called drag force $(F d)$ which is exerted by mudflow and is a destructive force against the pipelines.

Since clay (in mud form) as predominant deposit, then its essential movement (and/or its flow) is very necessary to be initially observed as basic representative mode of submarine sediment transport. Owing to the fact that clay is a material mostly contained in sediment deposits and also since it is the main material in every submarine slide event [6], hence, this experiment is limited to use mud only (without other granular material, such as sand and gravel).

The aim of this research is to investigate the collision event between mudflow and pipe stem in the course of laboratory simulation. The impact force and drag coefficient are determined by referring to rheological properties of mud model. The current experimental work was carried out in view of providing the basis for developing methods for prediction of the mudflow impact forces on pipe stem.

\section{Background}

In mudflows, since the rate of movement is fast enough, there is no time for excess pore water dissipation. The mechanics of this movement cannot be adequately explained by soil mechanics principles alone, as such, applying fluid mechanics principles is more necessary [13]. According to these principles, the analysis of flow behavior of submarine slide can be more appropriately studied using the gravity flow concept of fluid mechanics. Gravity flow concept has been widely used in research on fluid flow with two phases of different density that have addressed results of densities effects, speed of gravity current along the slope, and abrupt 
transitions between high viscosity fluids with the less one [1416].

The fluid dynamics approach was used to accommodate the additional effect of flow plasticity on the drag force related to the dynamic pressure which is proportional to mud density and the squared flow velocity [3]. Therefore, drag force generated by mudflow on pipe stem can be expressed by traditional fluid dynamic force and rheology properties of non-Newtonian fluid flow as the following equation [17].

$$
F d=\frac{1}{2} \cdot \rho_{f} \cdot C d \cdot A \cdot u^{2}
$$

where $F d$ is the drag force components perpendicular to pipe axis, $\rho_{f}$ is the mud density, $C d$ is the drag coefficient, $A$ is area of pipe stem which is facing opposite to mudflow direction, and $u$ is flow front velocity of mudflow.

As seen in (1), drag force analysis of this interaction is determined by mudflow's properties of density and velocity together with pipe's physical attribute of outside diameter (OD) and surface area. In addition, square velocity factor $\left(u^{2}\right)$ and coefficient of drag $(C d)$ are values obtained from flow measurement and calculation using (1) respectively. Thus, the two gives effect to each other since they have reciprocal correlation as seen in the expression of the following equations [18].

$$
C d=\frac{F d}{\frac{1}{2} \cdot \rho_{f} \cdot A \cdot u^{2}}
$$

Moreover, in order to generate the trend line of values of $C d$ in particular flow, it is correlated to Reynolds number $(R e)$, which is formulated as the following.

$$
R e=\frac{\rho_{f} \cdot u^{2}}{\mu \cdot \dot{\gamma}}
$$

where $\mu$ is mud viscosity, whereas $\dot{\gamma}$ is the shear rate. Reynolds number formulation involves fluid density and velocity factor in order to observe the ratio of inertial forces to viscous forces in term of flow condition. Previous studies revealed that when the propagation values of $C d$ and $R e$ are plotted in one graph, it shows the correlation that high values of $C d$ are generated at low values of $R e$ [19-21]. These expressions also explain the effect of square velocity, $u^{2}$, towards drag coefficient, $C d$.

\section{Experimental Program}

\section{A. Laboratory Equipment}

A technique to generate gravity flow named 'lockexchange system' was adopted, which meant separating two types of fluids that have different densities by using vertical barrier into two chambers. Then, the barrier is removed suddenly to let the denser fluid flow along the chamber's base in the ambient of less denser fluid. This method has been used in several fluid experiments including studies on two phases of fluids with different density factor [22-24] in which the effect of density ratio of two fluids have been investigated. It is worth mentioning that the current experimental work has been designed in a simple scheme; that is, generating a mudflow in water ambient using a lock-exchange system with gravity flow concept for further investigation of the characteristics of geophysical flows.

The concepts were implemented by development the main equipment of a rectangular channel of $8.53 \mathrm{~m}$ length, 0.25 width, and heights of $0.7 \mathrm{~m}$ and $1.30 \mathrm{~m}$ at the beginning and end point, respectively. It was designed and assembled at Hydrology Laboratory of Universiti Teknologi PETRONAS, Malaysia. In the experiment, the slope angle used was 3 degrees. The laboratory experiment was basically simulate a lump of mud, sliding into a pool of water then flowing over the surface of channel base and eventually colliding with the pipe stem at certain run-out distance.

Furthermore, Fig. 1 below shows the scheme of the experiment setup using a respective rectangular channel, which is divided into two main parts (i.e. chambers): mud and water. The two are separated by a vertical barrier (hereinafter referred to as gate). The section of $1 \mathrm{~m}$ along the base from sidewall until the gate was occupied by the mud, and then the water occupied the remaining section from gate until the end. The removable gate was pulled upward rapidly to let the mud start flowing into the water and collide with pipe model of OD $21.3 \mathrm{~mm}$, which is positioned at distance of $3.5 \mathrm{~m}$ from gate.

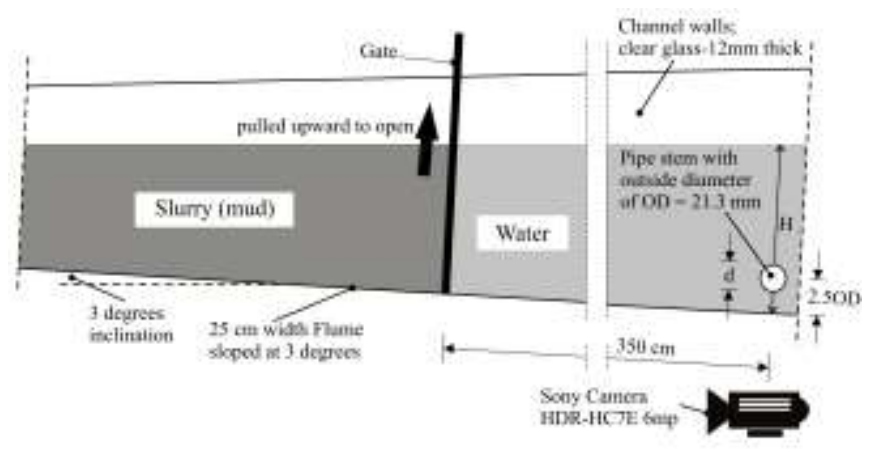

(a)

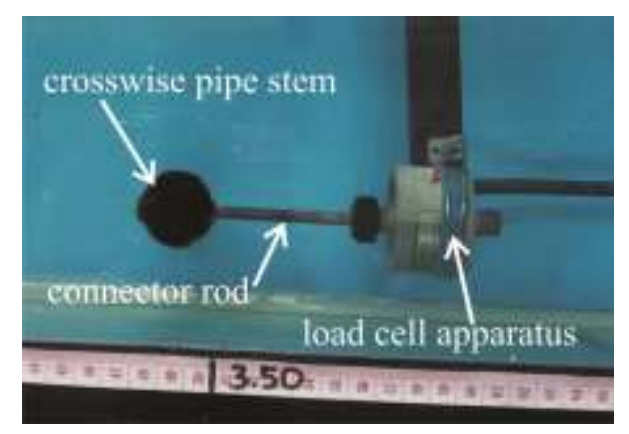

(b)

Figure 2. (a) Scheme of laboratory experiment setup; (b) load cell apparatus connected to pipe model.. 
Detail of assembly of pipe model connected to load cell apparatus is shown in Fig. 2(b). The current setup was using load cell type of DDEN-250N-RS485 with environmental protection of IP68 to $10 \mathrm{~m}$ depth. A data logger device of 'Smart Dynamic Strain Recorder' SDSR of DC-204R series was used to record the force responses of the load cell, which represent the force generated during collision between mudflow and pipe model.

\section{B. Material and Rheological Properties}

Mixtures of refined kaolin and water were used as mud model in this experiments which has density of $\rho_{f}$, whereas, water has density of $\rho_{w}$, where $\rho_{f}>\rho_{w}$. Refined kaolin of AKIMA 45 is fabricated by the local kaolin industry of Malaysia with specific gravity (GS) value about 2.6. Percentage variations of kaolin clay content (hereinafter abbreviated as $\mathrm{KCC}$ ) were in range $10 \%$ to $35 \%$, with $5 \%$ increment.

Current experiments used a fixed volume of 45 and 67.5 liters of slurry, which is made through mixing process of weight base of either kaolin or water. Rheological test, including density and viscosity was carried out by using common equipment in oil and gas industry those are Fann Model 35 Viscometer and Mud Balance Model 140. It was used primarily in the stage of drilling in the oil wells exploration process.

The instruments and test kits were designed to conform to the testing standards established by the American Petroleum Institute (API) and published in API SPEC 10, API RP 10B-2, API SPEC 13A, API RP 13B-1, 13B-2, 13D, 13I, 13J, and $13 \mathrm{~K}$, and they were suitable for field and laboratory uses. In order to complete and verify the rheology test results, mud models were also re-tested using Brookfield Digital Viscometer DV-I+ equipment, according to ASTM D2196 [25].

\section{Iv. Result and Discussion}

\section{A. Rheological Properties}

The rheology of clay-water mixture is possible to fit the experimental values in a wide shear rate ranges including values as small as 0.01 per second (or $0.01 \mathrm{~s}^{-1}$ ) into the Herschel-Bulkley model. It also provides a theoretical yield stress which is very close to real yield stress, with a low level of uncertainty for conventional practical application [26].

Even though the linear viscoplastic Bingham model is the most commonly used to describe rheology of debris or mudflow, the Herschel-Bulkley model has been found to be more appropriate for describing the nonlinear viscoplastic behavior of debris flows [27-28]. Therefore, in the current studies, Herschel-Bulkley model is adopted to characterize the mud rheological behavior and is expressed as in the following equation.

$$
\left(\tau-\tau_{c}\right)=K \cdot \dot{\gamma}^{n}
$$

where, $\tau_{c}$ is the yield strength, $K$ is equivalent to the dynamic viscosity, and $n$ is positive parameters of model factor [26].

According to rheological test series, $\tau$ values of each percentage KCC at certain $\dot{\gamma}$ were obtained and plotted in a graph with $\dot{\gamma}$ as a function of $\tau$. Based on the respective graph, Herschel-Bulkley models are formulated using curve fitting method. Solver of least squares approach is employed to generate the fitting curve equation with approximation error as expressed as follow;

$$
e r r=\sum_{i=1}^{N}\left(\tau_{i}-\left(\tau_{c i}+K_{i} \cdot \dot{\gamma}_{i}^{n}\right)\right)^{2}
$$

where $N$ is the number of variation values of $\dot{\gamma}$ applied in test. Here, $N$ has value of 8 , according to number of spindle RPM of Brookfield Digital Viscometer DV-I+ equipment.

TABLE I. RHEOLOGICAL TEST RESULTS OF MUD FOR EACH PERCENTAGE OF KCC AND HERSCHEL-BULKLEY RHEOLOGICAL MODELS

\begin{tabular}{|c|c|c|c|}
\hline $\begin{array}{c}\text { KCC } \\
(\%)\end{array}$ & $\begin{array}{c}\text { Density } \\
\left(\rho_{f}\right) \\
\left(\mathrm{kg} / \mathrm{m}^{3}\right)\end{array}$ & $\begin{array}{c}\text { Specific } \\
\text { Gravity } \\
(\mathbf{G S})\end{array}$ & $\begin{array}{c}\text { Herschel-Bulkley } \\
\text { rheological model }\end{array}$ \\
\hline 10 & 1054 & 1.07 & $\tau=0.6+0.73 \dot{\gamma}^{0.3}$ \\
\hline 15 & 1092 & 1.10 & $\tau=1.71+1.63 \dot{\gamma}^{0.27}$ \\
\hline 20 & 1134 & 1.13 & $\tau=3.4+4.73 \dot{\gamma}^{0.32}$ \\
\hline 25 & 1152 & 1.20 & $\tau=3.57+8.88 \dot{\gamma}^{0.4}$ \\
\hline 30 & 1236 & 1.23 & $\tau=5.7+12.68 \dot{\gamma}^{0.42}$ \\
\hline 35 & 1266 & 1.27 & $\tau=9+20.36 \dot{\gamma}^{0.5}$ \\
\hline
\end{tabular}

In the end, Fig. 3 shows the mud rheological test results and Herschel-Bulkley model fit, with $R^{2}$ in range of $98.9 \%$ to 99.6\%. Moreover, rheological test results are listed in Table 1 as well as the equation of Herschel-Bulkley model of the mud according to percentage of KCC.Rheological test results of mud for each percentage of KCC and Herschel-Bulkley rheological models.

The dataset of rheological properties test in Table 1 represents the propagation of density magnitudes among material models based on percentage of KCC. Fann Mud Balance results values of mud densities in range of $1054 \mathrm{~kg} / \mathrm{m}^{3}$ to $1266 \mathrm{~kg} / \mathrm{m}^{3}$. Furthermore, Herschel-Bulkley model shows increment of yield strength, $\tau_{c}$, in the range $0.6 \mathrm{~Pa}$ to $9.0 \mathrm{~Pa}$. It can be inferred that both $\tau_{c}$ and $\rho$ are increasing in accordance with increment of KCC. And then, by using data listed in Table 1, Herschel-Bulkley rheological model as expressed in Eq.(4) and laboratory results of the shear stress characteristics of mud model are presented in the graph of shear rate $(\dot{\gamma})$ as a function of shear stress $(\tau)$ as shown in Fig. 3. Figure 3 shows that Herschel-Bulkley model are fitting laboratory tests very well even for low applied shear rate test. Hereinafter, the rheological properties, which are used in analysis and 
Proc. of the Third Intl. Conf. on Advances in Civil and Structural Engineering - CSE 2015

Copyright $(\odot$ Institute of Research Engineers and Doctors, USA .All rights reserved.

ISBN: 978-1-63248-057-6 doi: 10.15224/ 978-1-63248-057-6-47

discussions, are referred to Herschel-Bulkley model displayed in Fig. 3 and listed in Table 1.

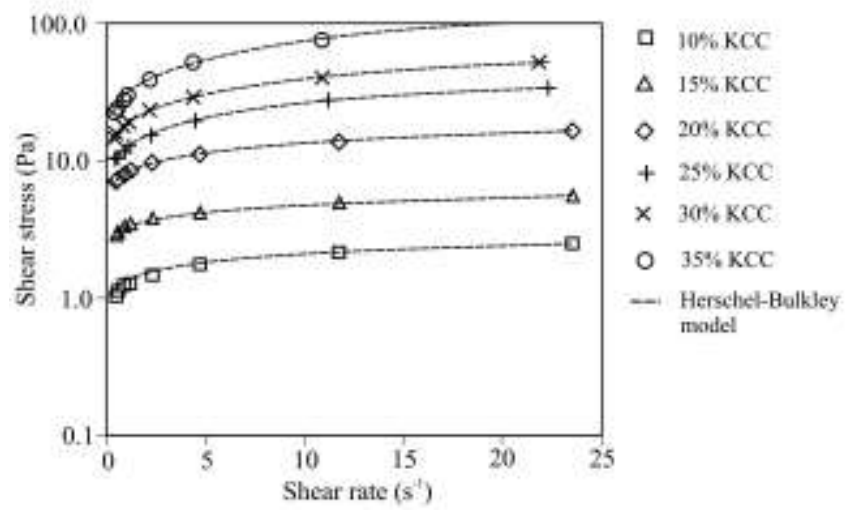

Figure 3. Mud rheological test and Herschel-Bulkley model fit.

The mud rheological test and Herschel-Bulkley model fits in Fig. 3 show that the mud models properties were probably best described as non-Newtonian pseudoplastic fluid with shear rate increases and were exhibiting thixotropic shearthinning. According to shear-thinning fluids, the apparent viscosity, $\mu_{\mathrm{app}}$, is described by dividing the shear stress by the shear rate, thus

$$
\mu_{a p p}=\frac{\tau_{c}}{\dot{\gamma}}+K \cdot \dot{\gamma}^{n-1}
$$

Density factor is important and closely considered for observations and analyses based on the principles of gravity flow. The Boussinesq approximation may be applied regarding initial density ratios, denoted as $\rho_{i}$, in order to check the effects of density variations towards inertia. Initial density ratio is formulated as follow [16].

$$
\rho_{i}=\left[\left(\rho_{f}-\rho_{w}\right) /\left(\rho_{f}+\rho_{w}\right)\right]^{1 / 2}
$$

Referring to Table 1, the mud used for this experiment has value of $\rho_{i}$ in range 0.17 to 0.27 for KCC below $25 \%$, whereas $30 \%$ and $35 \%$ have value of 0.33 and 0.34 , respectively. Furthermore, density ratios $\left(\rho_{r}\right)$ are calculated using equation of $\rho_{r}=\rho_{w} / \rho_{f}$ which is yielding values in range of 0.790 to 0.949 . Since $0.6<\rho_{r}<1$ was achieved, it was possible to approach these mudflows experiment using non-Boussinesq flow concept [23].

\section{B. Simulation Results}

Each mud models of $10 \%$ to $30 \% \mathrm{KCC}$ had a relative small fluctuation of flow front velocity in range of $0.237 \mathrm{~m} / \mathrm{s}$ to $0.289 \mathrm{~m} / \mathrm{s}$ at run-out distance of $3.5 \mathrm{~m}$ (i.e. at pipe position). Based on velocity values, experiments addressed value of Reynolds number, $R e$ ranged from 1.34 to 40.14 . For an example, Fig 4. shows the consecutive mudflows images captured of $15 \%$ KCC mud during collision against suspended pipe stem with $H / d$ ratio of 18.3 .
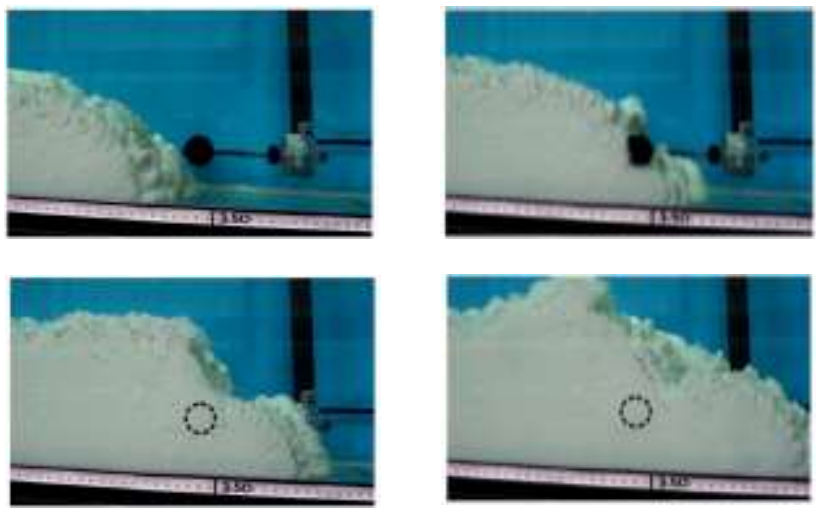

Figure 4. Image sequence of collision event of $15 \%$ KCC.

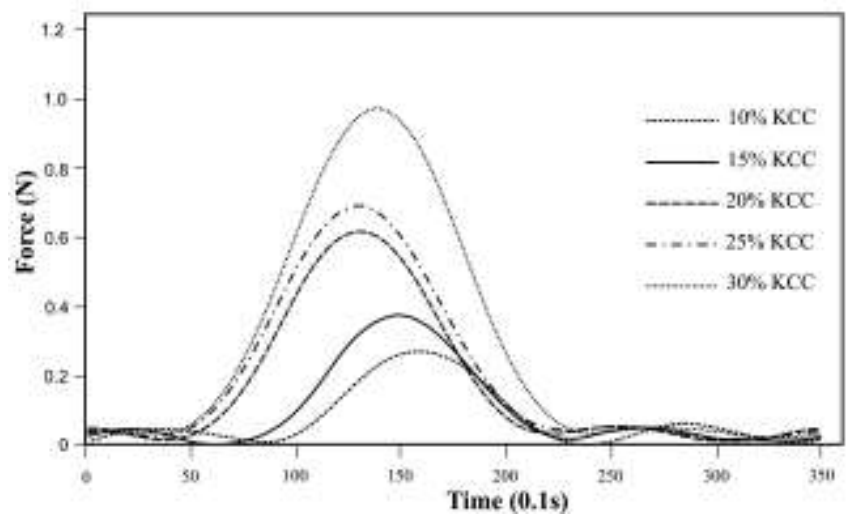

Figure 6. Drag forces exerted by mudflow on pipeline.

Figure 6 shows examples of the typical responses of drag force exerted by mudflow for each percentage of KCC that addressed the maximum drag force of all current experiments in range of $0.248 \mathrm{~N}$ to $1.104 \mathrm{~N}$. Coefficients of drag forces $(C d)$ are calculated based on the maximum values of $F d$ for each percentage of KCC because in order to observe the maximum impact of mudflow to pipe model.

\section{v. Concluding Remark}

Experimental work series of collision between mudflow and crosswise pipe stem was performed to investigate the characteristics of drag force exerted by mudflow and related drag coefficient. Mud model was mixtures of kaolin and water with densities in the range of $1054 \mathrm{~kg} / \mathrm{m}^{3}$ to $1266 \mathrm{~kg} / \mathrm{m}^{3}$. Herschel-Bulkley rheological model fitted very well the rheological properties, which were tested using Brookfield Digital Viscometer DV-It.

Overall, $H / d$ ratio of 23.15 generated values of collision attributes higher than $H / d$ ratio of 18.3 with differences in range of $3 \%$ to $32 \%$. Furthermore, $\mathrm{Re}-\mathrm{Cd}$ relationship was suitably expressed as Power-law model that were $C d=3.3 R e^{(-0.4)}$ and $C d=3.68 R e^{(-0.37)}$. 


\section{Acknowledgment}

The first outhor thanks to Research Innovation Office of Universiti Teknologi PETRONAS for research facilities. Authors to thank to Universitas Sarjanawiyata Tamansiswa (UST) for providing the research services.

\section{References}

[1] F. Nadim, "Challenges to geo-scientists in risk assessment for submarine slides," Norwegian Journal of Geology, vol. 86, pp. 351-362, 2006.

[2] S.-K. Hsu, J. Kuo, C.-L. Lo, C.-H. Tsai, W.-B. Doo, C.-Y. Ku, and J.C. Sibuet, "Turbidity Currents, Submarine Landslides and the 2006 Pingtung Earthquake off SWTaiwan," Terr. Atmos. Ocean. Sci., vol. 19, pp. 767-772, 2008.

[3] R. Bruschi, S. Bughi, M. Spinazze, E. Torselletti, and L. Vitali, "Impact of debris flows and turbidity currents on seafloor structures," Norwegian Journal of Geology, vol. 86, pp. 317-337, 2006.

[4] F. V. D. Blasio, L. Engvik, C. B. Harbitz, and A. Elverhøi, "Hydroplaning and submarine debris flows," Journal of Geophysical Research, vol. 109, pp. 1-15, 2004.

[5] A. Elverhoi, C. B. Harbitz, P. Dimakis, D. Mohrig, J. Marl, and G. Parker, "On the dynamics of subaqueous debris flows," Oceanography, vol. 13, pp. 109-117, 2000.

[6] J. J. Hance, "Development of a Database and Assessment of Seafloor Slope Stability based on Published Literature," Master of Science in Engineering, Faculty of the Graduate School, The University of Texas, Austin, 2003.

[7] P. Bryn, K. Berg, C. F. Forsberg, A. Solheim, and T. J. Kvalstad, "Explaining the Storegga Slide," Marine and Petroleum Geology, vol. 22, pp. 11-19, 2005.

[8] A. E. Fallick, C. I. Macaulay, and R. S. Haszeldine, "Implications of linierly correlated oxygen and hydrogen isotopic compositions for kaolinite and illite in the Magnus Sandstone, North Sea.," Journal of Clays and Clay Minerals, vol. 41, pp. 184-190, 1993.

[9] J. S. Youn, J. C. Byun, and S. H. Lee, "Sedimentary Strata and Clay Mineralogy of Continental Shelf Mud Deposits in the East China Sea," International Journal of Oceans and Oceanography, vol. 1, pp. 183-194, 2006

[10] C. Martín-Puertas, M. P. Mata, M. C. Fernández-Puga, V. D. d. Río, J. T. Vázquez, and L. Somoza, "A comparative mineralogical study of gas-related sediments of the Gulf of Cádiz," Geo Marine Letter, vol. 27, pp. 223-235, 2007.

[11] G. Nichols, Sedimentology and Stratigraphy. Oxford, 1999.

[12] D. C. Mosher, L. Moscardelli, R. C. Shipp, J. D. Chaytor, C. D. P. Baxter, H. J. Lee, and R. Urgeles, "Submarine Mass Movements and Their Consequences," in Submarine Mass Movements and Their Consequences, Advances in Natural and Technological Hazards Research. vol. 28, D. C. Mosher, et al., Eds., New York: Springer, 2010, pp. 1-8.

[13] J. Locat and H. J. Lee, "Submarine Landslides: Advances and Challenges," presented at the The 8th International Symposium on Landslides, Cardiff, U.K, 2000.
[14] M. A. Hallworth and H. E. Huppert, "Abrupt transitions in highconcentration, particle-driven gravity currents," Physics of Fluids, vol. 10, pp. 1083-1087, 1998.

[15] S. J. Lentz and K. R. Helfrich, "Bouyant gravity currents along a sloping bottom in a rotating fluid," Journal of Fluid Mechanics, vol. 464, pp. 251-278, 2002.

[16] L. A. Amy, A. J. Hogg, J. Peakall, and P.J.Talling, "Abrupt transitions in gravity currents," Journal of Geophysical Research, vol. 110, pp. 1-19, 2005.

[17] H. Pazwash and M. Robertson, "Forces on Bodies in Bingham fluids," Journal of Hydraulic Research vol. 13, pp. 35-55, 1975.

[18] M. Georgiadis, "Landslide Drag Forces on Pipelines," Japanese Society of Soil Mechanics and Foundation Engineering, vol. 31, pp. 156-161, 1991.

[19] A. Zakeri, K. Høeg, and F. Nadim, "Submarine debris flow impact on pipelines - Part I: Experimental investigation," Coastal Engineering, vol. 55, pp. 1209 - 1218, 2008.

[20] A. Zakeri, K. Høeg, and F. Nadim, "Submarine debris flow impact on pipelines - Part II: Numerical analysis," Coastal Engineering, vol. 56, pp. 1-10, 2009.

[21] S. Nakajo, Y. Takeoka, and T. Shigematsu, "Numerical simulation of fluid force acting on circular cylinders in unidirectional flow," in 7th International Symposium On Turbulence and Shear Flow Phenomena (TSFP-7), Ottawa, Canada, 2011.

[22] J. O. Shin, S. B. Dalziel, and P. F. Linden, "Gravity currents produced by lock exchange," Journal of Fluid Mechanics, vol. 521, pp. 1-34, 2004.

[23] R. J. Lowe, J. W. Rottman, and P. F. Linden, "The non-Boussinesq lock-exchange problem. Part 1. Theory and experiments," Journal of Fluid Mechanics, vol. 537, pp. 101-124, 2005.

[24] V. K. Birman, B. A. Battandier, E. Meiburg, and P. F. Linden, "Lockexchange flows in sloping channels," Journal of Fluid Mechanics, vol. 577, pp. 53-77, 2007.

[25] Standards, "ASTM D1092-05 Standard Test Methods for Rheological Properties of Non-Newtonian Materials by Rotational (Brookfield type) Viscometer.", ASTM International, 2005.

[26] P. Coussot, Mudflow Rheology and Dynamics. Rotterdam: AA Balkema, 1997.

[27] N. J. Balmforth, R. V. Craster, and R. Sassi, "Shallow viscoplastic flow on an inclined plane," Journal of Fluid Mechanics, vol. 470, pp. 1-29, 2002.

[28] S. Cohard and C. Ancey, "Experimental investigation of the spreading of viscoplastic fluids on inclined plane," Journal of Non-Newtonian Fluid Mechanics, vol. 158, pp. 73-84, 2009. 